\title{
BAUSINGER, Hermann, BEYRER, Klaus, KORFF, Gottfried, Reisekultur. Von der Pilgerfahrt zum modernen Tourismus
}

\section{Patrice Veit}

\section{OpenEdition}

\section{Journals}

Édition électronique

URL : http://journals.openedition.org/ifha/1918

DOI : $10.4000 /$ ifha. 1918

ISSN : 2198-8943

Éditeur

IFRA - Institut franco-allemand (sciences historiques et sociales)

Référence électronique

Patrice Veit, «BAUSINGER, Hermann, BEYRER, Klaus, KORFF, Gottfried, Reisekultur. Von der Pilgerfahrt zum modernen Tourismus », Revue de l'IFHA [En ligne], Date de recension, mis en ligne le 01 janvier 1995, consulté le 22 septembre 2020. URL : http://journals.openedition.org/ifha/1918 ; DOI : https:// doi.org/10.4000/ifha.1918

Ce document a été généré automatiquement le 22 septembre 2020.

(CIFHA 


\title{
BAUSINGER, Hermann, BEYRER, Klaus, KORFF, Gottfried, Reisekultur. Von der Pilgerfahrt zum modernen Tourismus
}

\author{
Patrice Veit
}

1 Sous la forme d'une cinquantaine de miniatures pourvues d'une riche illustration et dans une perspective largement interdisciplinaire, ce livre propose un panorama de la "culture du voyage« depuis le milieu du XVIIe s. tout en concentrant l'essentiel de son observation sur la période (à partir de la fin du XVIIIe s.) où l'on assiste à une véritable "révolution« dans la notion de voyage en même temps qu'apparaissent peu à peu ses formes modernes et qu'il devient progressivement une fin en soi. L'ouvrage aborde ainsi les différents types de voyage, du pèlerinage jusqu'aux voyages organisés, et les différentes sortes de voyageurs, du vagabond au savant en passant par les marchands, les colporteurs, les musiciens, les émigrants etc.; il en dégage certains buts préférés que constituent, par exemple, les Alpes suisses et leur air vivifiant aux XVIIIe et XIXe s., le Paris révolutionnaire au fort pouvoir d'attraction auprès des Allemands, l'Angleterre et son développement technique et industriel ou les expositions universelles; il en illustre les moyens de transport (sur terre, sur l'eau et dans les airs), leurs progrès techniques et leur rôle dans la transformation même du voyage et de son idée. Mais l'évasion peut aussi se cantonner aux quatre murs de la maison comme le montre la lecture des romans d'aventure et des récits de voyage à partir du XVIIIe s. ou les jeux qui pénètrent les chambres des enfants de la bourgeoisie au XIXe s. En retraçant ainsi l'histoire du voyage dans la longue durée jusqu'à l'époque contemporaine, ses acteurs, ses moyens et ses circonstances, l'ouvrage s'interroge en même temps sur les transformations culturelles et sociales que ses différentes formes révèlent ou permettent d'éclairer.

Patrice VEIT 